\title{
Análise cartográfica da área de proteção ambiental do Itapiracó São Luís/MA (Brasil)
}

Existem diferentes mecanismos de proteção ambiental, um deles é o instrumento de gestão da Política Nacional de Meio Ambiente: a criação de espaço especialmente protegidos do tipo Unidades de Conservação da Natureza, que garante proteção aos recursos naturais naquele espaço. Considerando as premissas da sustentabilidade ambiental, o Estado do Maranhão instituiu a Área de Proteção Ambiental do Itapiracó, porém essa proteção concedida pelo diploma legal da APA não conseguiu seus objetivos, tanto por falhas na definição da poligonal, quanto na implementação da APA, o que culminou com o desconhecimento da população sobre este espaço protegido e suas funções ambientais. O presente trabalho analisou de forma crítica a redação do Decreto Estadual $n$. 15.618/1997, o qual cria a APA do Itapiracó, averiguando a descrição apresentada e mencionando alguns problemas redacionais, assim como interpretativos. Deste modo, ficou evidente a necessidade de atualização da norma devido à ausência de parâmetros de exatidão cartográfica, tendo em vista a constatação da ineficiência da norma para estabelecer a poligonal referente a APA do Itapiracó e, consequentemente, em proteger as nascentes do Riacho Itapiracó.

\section{Cartographic analysis of the environmental protection area from Itapiracó São Luís/MA (Brazil)}

\begin{abstract}
There are several different mechanism of environmental protection one of them is the management instrument of the National Environment Policy: the creation of spaces specially protected as Nature Conservation Units ensuring protection of natural resources in that space. Considering the premisses of environmental sustainability, the state of Maranhão established the Itapiracó Environmental Protection Area however this protection granted by the APA legal diploma did not achieve its objectives due to failures in the definition of polygonal, as inthe implementation of the APA which culminated in the population's lack of knowledge about this protected space and its environmental functions. The presente work critically analyzed the state decree of redaction the $n^{\circ} 15.618 / 1997$, which creates the Itaparacó APA investigating the description presented and mentioning some editorial problems as well as interpretative problems. Thus was evidente the need to update the standard due to the cartographic accuracy parameters absence in view of the confirmation inefficiency norm for establish the polygonal reffering to the Itapiracó APA and consequently to protect the springs of Itaparacó stream.
\end{abstract}

Keywords: Conservation Unit; Cartography; Territorial Management.

Topic: Engenharia Ambiental

Reviewed anonymously in the process of blind peer
Received: 05/08/2020

Approved: 26/09/2020
Gilney Soares Nascimento (iD)

Universidade Federal do Maranhão, Brasil http://lattes.cnpq.br/9149963206696860 http://orcid.org/0000-0002-7314-1440 gilney sn@hotmail.com

Janaina Gomes Dantas (iD)

Instituto de Educação Ciência e Tecnologia do Maranhão, Brasil

http://lattes.cnpq.br/8324836453845133 http://orcid.org/0000-0002-5401-7452

janainnadantas@gmail.com

Marcos André Capitulino de Barros Filho Universidade Federal do Maranhão, Brasil http://lattes.cnpq.br/8824952610047891 http://orcid.org/0000-0003-1827-8724 marcos.capitulino@ufma.br

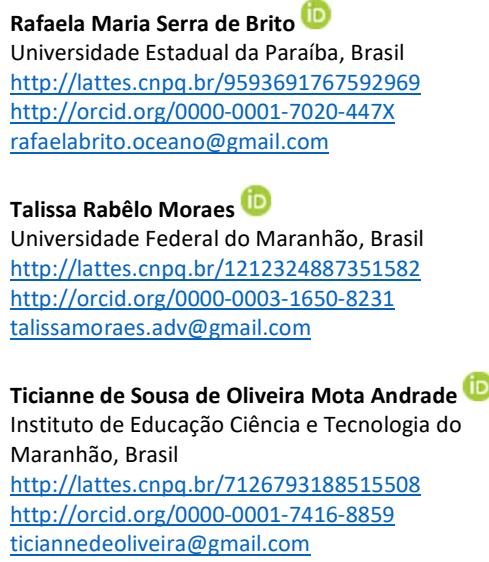

Ticianne de Sousa de Oliveira Mota Andrade (it) Instituto de Educação Ciência e Tecnologia do Maranhão, Brasil

http://lattes.cnpq.br/7126793188515508

http://orcid.org/0000-0001-7416-8859

ticiannedeoliveira@gmail.com

Herbert Senzano Lopes
Universidade Federal do Rio Grande do Norte,
Brasil
http://lattes.cnpq.br/9669152092439524
$\underline{\text { http://orcid.org/0000-0002-5830-7369 }}$
herbertsenzano@gmail.com
Patrícia Cristina de Araújo Puglia de Carvalh
(1)
Universidade Federal do Rio Grande do Nort
Brasil
http://lattes.cnpq.br/8083088748017565
http://orcid.org/0000-0002-3630-874X
pcpuglia@hotmail.com
Wenderson Carlos da Silva Teixeira (1D
Universidade Estadual do Maranhão, Brasil
http://lattes.cnpq.br/7720018283496713
http://orcid.org/0000-0002-0540-9388
teixeira@imesc.ma.gov.br

Referencing this:

NASCIMENTO, G. S.; DANTAS, J. G.; BARROS FILHO, M. A. C.; BRITO, R. M. S.; MORAES, T. R.; ANDRADE, T. S. O. M.; LOPES, H. S.; CARVALHO, P. C. A. P.; EIXEIRA, W. C. S.. Análise cartográfica da área de proteção ambiental do Itapiracó São Luís/MA (Brasil). Revista Ibero Americana de Ciências Ambientais, v.11, n.5, p.309-316, 2020. DOI: http://doi.org/10.6008/CBPC2179-6858.2020.005.0029 


\section{INTRODUÇÃO}

A Área de Proteção Ambiental do Itapiracó (APA.) integra o Sistema Estadual de Unidade de Conservação do Estado do Maranhão, e está inserida nas Unidades de Uso Sustentável, de acordo com o Decreto Estadual n 15.618, de 23 de junho de 1997, o qual cria a APA do Itapiracó e dá outras providencias (MARANHÃO, 1997).

O processo evolutivo de ocupação do território ludovicense tornou necessário a atuação e o seguimento de metodologias que façam frente ao tipo de gestão territorial. Desta forma, após a homologação da lei n 10.649, de 31 de julho de 2017, a qual atualiza a Divisa Intermunicipal de São José de Ribamar e São Luís (MARANHÃO, 2017), houve a necessidade de analisar cartograficamente, confrontando o que se acredita ser a APA do Itapiracó, com os dados disponibilizados pelos órgãos competentes. Resultado esse, devido à ausência de diagnósticos que relatem suas especificidades e potencialidades, e ainda a necessidade de implantação de parâmetros técnico-cartográficos nas normas que criaram essas unidades de conservação, fato que impulsionou a produção da presente análise.

Nesse sentido, o presente trabalho realizou uma análise cartográfica e examinou de forma crítica a redação do Decreto Estadual n 15.618, de 26 de junho de 1997, o qual cria a APA do Itapiracó, averiguando a descrição apresentada e mencionando alguns problemas redacionais, assim como interpretativos.

\section{RELATO}

A APA do Itapiracó está inserida na Região Nordeste do Brasil, Estado do Maranhão, integrando a Região Geográfica Imediata de São Luís (BRASIL, 2017). De acordo com a Lei Complementar n 174/2015, que dispõe sobre a instituição e gestão da região metropolitana, a APA está incluída na Região Metropolitana da Grande São Luís (MARANHÃO, 2015), por outro lado, segundo a norma n 10.649/2017, que atualiza a Divisa Intermunicipal de São José de Ribamar e São Luís - MA, localiza-se tanto na área territorial do Município de São Luís, quanto no Município de São José de Ribamar. A figura 01 apresenta a localização geográfica da APA do Itapiracó.

A APA possui como vértice central as coordenadas geográficas $02^{\circ} 31^{\prime} 25.76012^{\prime \prime}$ de latitude Sul; $44^{\circ}$ 12' 13.95190" de longitude Oeste (Datum: Sirgas-2000), apresentando área aproximada de trezentos e cinquenta e cinco hectares ( 355 ha), e perímetro de dez mil e cinquenta e nove metros (10.059m), conforme dados do Sistema Nacional de Unidades de Conservação (BRASIL, 2000). São seus limites ou confrontantes: ao Norte, Conjuntos Habitacionais Canudos e Terra Livre; à Leste, Conjunto Habitacional Alto do Itapiracó; ao Sul, Bairros Cohabiano, Cohatrac e Chácara Itapiracó; e a Oeste, Bairro Ipem Turu e Conjuntos Habitacionais Matões e Solar dos Lusitanos.

Com base nas instruções reguladoras das normas técnicas da cartografia nacional, disposta no Decreto no 89.817/1984 (BRASIL, 1984), bem como observando o respectivo Padrão de Exatidão Cartográfica $(\mathrm{PEC})$, recomendado para detectar, com exatidão de alocação, os vértices de limite que consolidam a poligonal referente à APA do Itapiracó, e ainda conforme Decreto Estadual no 15.618 (MARANHÃO, 1997), 
as coordenadas dos vértices de limite foram inseridas no Sistema de Informação Geográfica (do acrónimo do inglês GIS - Geographic Information System), software GPS TrackMaker PRO (versão 4.8,) e convertidas do Datum SAD-69 para o SIRGAS-2000, para sobrepor os dados em bases cartográficas, aerofotos e imagens de satélite para comprovação da localização. Posteriormente, os dados foram digitalizados em laboratório no software AutoCAD Map 3D (versão 2019), em conjunto com software ArcGIS, versão 10.5 (ENT-ES-0006-17 IMESC - 0117), para confecção de cartas técnicas, com vistas a auxiliar no esclarecimento e compreensão da análise, levando em consideração interpretações acerca do tema levantado.

Para efeito da pesquisa qualitativa aqui relatada, a partir do método hipotético-dedutivo (SPOSITO, 2004) foram utilizadas as seguintes etapas: a) Pesquisa bibliográfica, realizada através de livros, periódicos e similares, pesquisa documental, através de levantamento de dispositivos legais e relatórios técnicos; b) Visitas técnicas na Área de Proteção Ambiental do Itapiracó (realizada nos dias 12 e 14/09/2019); c) Processamento Laboratorial dos dados cartográficos; d) Período da pesquisa: agosto à novembro de 2019.
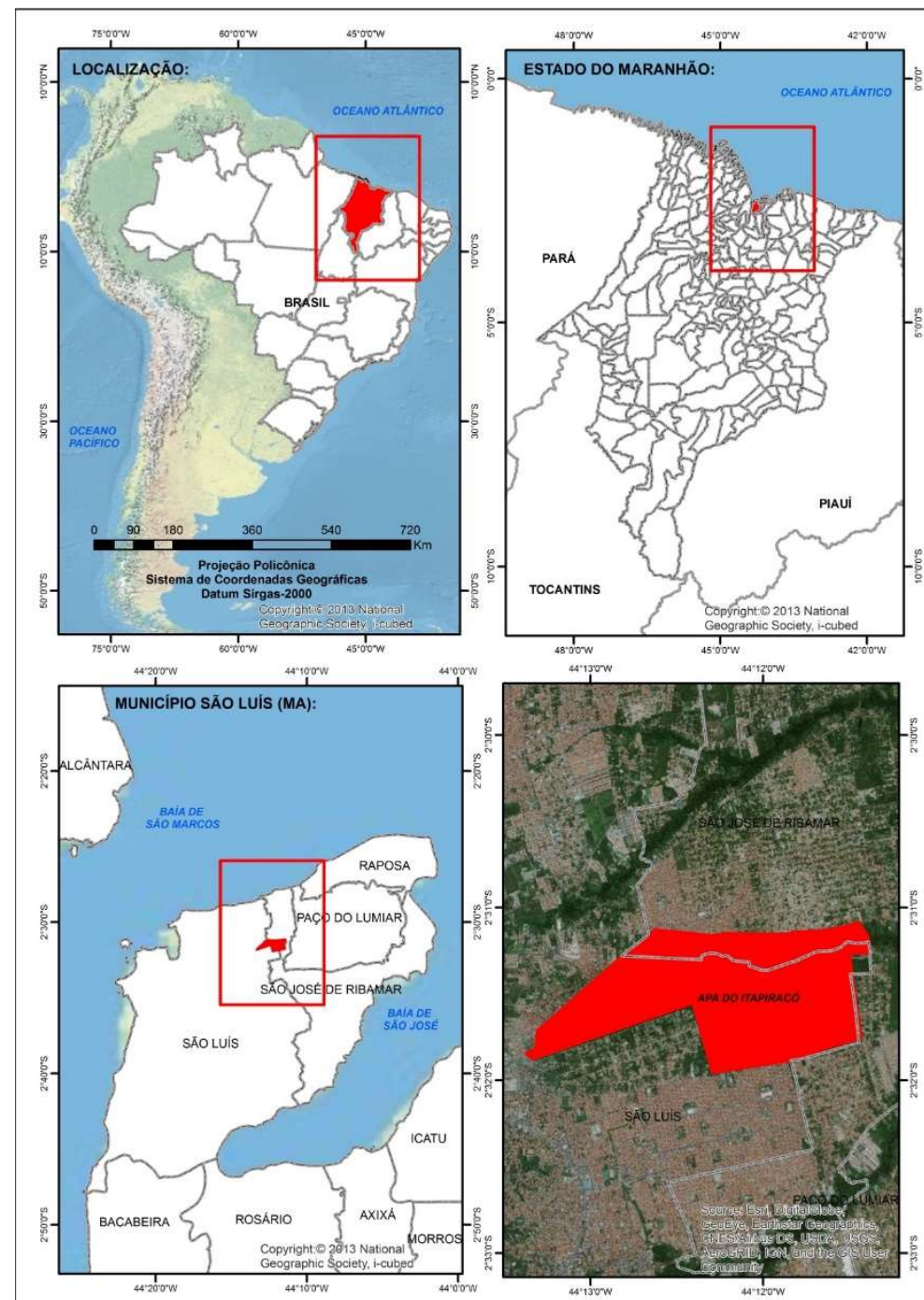

Figura 1: Localização geográfica da Área de Proteção Ambiental do Itapiracó, São Luís (MA).

Assim, para o presente diagnóstico, todas as coordenadas aqui descritas estão plotadas nas Cartas de Localização, como também georreferenciadas ao Sistema Geodésico Brasileiro, e encontram-se representadas na Projeção Universal Transversa de Mercator (UTM), Zona: 23M, referenciadas ao Meridiano 
Central de $45^{\circ}$, tendo como Datum Horizontal o SIRGAS-2000 (Elipsoide: GRS-80/ Sistema de Referência Geocêntrico das Américas). A execução do levantamento in situ atende aos parâmetros estabelecidos pelos órgãos competentes, como Especificações e Normas Gerais para Levantamentos com GPS (BRASIL, 1993), tanto quanto Normas Técnicas para Levantamentos Topográficos (BRASIL, 2001). Todos os azimutes e distâncias foram calculados no plano de projeção UTM.

Os Metadados foram elaborados em conformidade com o Decreto Federal no 6.666/2008, que criou a Infraestrutura Nacional de Dados Espaciais (BRASIL, 2008), especificado pelas Normas, Padrões e Especificações Técnicas e norma ISO 19115 (IOS, 2003) com objetivo de descrever as características, possibilidades e limitações através de informação estruturada e documentada.

\section{DISCUSSÃO}

Nas especificações do Decreto Estadual no 15.618/1997, o qual cria a Área de Proteção Ambiental do Itapiracó e dá outras providencias (MARANHÃO, 1997):

Art. 2ㅇ - A Área de Proteção Ambiental do Itapiracó, com uma área de 322ha (trezentos e vinte e dois hectares), abrangendo mata de galeria, que protege as nascentes do riacho Itapiracó, tem os seguintes limites: ao Norte, Conjunto Parque Vitória; ao Sul, Condomínio Itapiracó; a Oeste, Conjunto IPEM Turu; a Leste, Conjunto COHATRAC e Loteamento SOTERRA. Parágrafo Único - A área de que trata este artigo, localizada entre as latitudes de

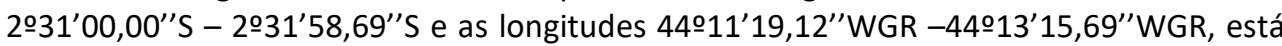
compreendida dentro do seguinte perímetro: inicia no ponto de coordenadas geográficas latitude 2031'45,46"S e longitude 4413'10,92”'WGR localizado a norte do baixo do Anil, precisamente o Condomínio Itapiracó (Ponto 1); parte daí até o ponto de coordenadas

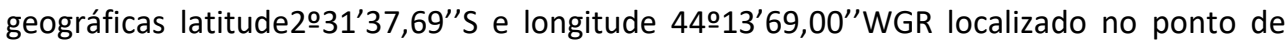
convergência do Condomínio com o terreno da TURUSA (Ponto 2);

É comum que se encontrem diferenças entre as redações das normas territoriais e o que se apresenta na realidade, e nesse caso não é diferente. Confrontando o que se acredita ser hoje a APA do Itapiracó e a descrição apresentada, apontam-se alguns problemas redacionais, assim como interpretativos. No trecho da redação “(...) inicia no ponto de coordenadas geográficas latitude 2³1'45,46"S e longitude 4413'10,92"WGR localizado a norte do baixo do Anil, precisamente o Condomínio Itapiracó (Ponto 1) (....)" (MARANHÃO, 1997) a interpretação que se tem é que o vértice de limite esteja confrontando com o Condomínio Itapiracó, entretanto o vértice mencionado localiza-se no interior da APA do Itapiracó. Apesar do uso de coordenadas geográficas para determinar o vértice de limite ser um padrão técnico, o vértice mencionado não condiz com a sapiência da exatidão de alocação do ponto supracitado, ou seja, não se situa na extremidade da APA do Itapiracó.

Em seguida, o trecho "parte daí até o ponto de coordenadas geográficas latitude 2²1’37,69"S e longitude 4413'69,00"WGR localizado no ponto de convergência do Condomínio com o terreno da TURUSA (Ponto 2) [grifos nossos]" (MARANHÃO, 1997), apesar de fazer referência de direção a um determinado lugar, o uso do termo não é um parâmetro técnico, pois não expressa exatidão cartográfica. Quando o correto seria utilizar "rumo" ou "azimute", que determinam um direcionamento e, consequente localização. Outra observação é referente ao uso dos confrontantes (bairros, propriedades ou terrenos limítrofes) da APA do 
Itapiracó, como por exemplo, Condomínio Itapiracó e terreno da Turusa, pois atualmente não se detecta suas alocações.

É importante destacar ainda o equívoco na descrição da coordenada: latitude 2031'37,69"S e longitude 4413'69,00”WGR. Um sistema de coordenadas geográficas é um sistema de referência usado para posicionar e mensurar feições geográficas, estas, medidas em graus de longitude e latitude. Os valores de longitude variam de $0^{\circ}$ até $180^{\circ}$ no hemisfério leste, começando no meridiano de Greenwich (Inglaterra). No hemisfério oeste, a longitude varia de $0^{\circ}$ até $180^{\circ}$, iniciando, também, no meridiano de Greenwich. Os valores de latitude variam de $0^{\circ}$ até $90^{\circ}$ no hemisfério norte, indo do equador até o polo norte. No hemisfério sul, a latitude varia de $0^{\circ}$ até $-90^{\circ}$, indo do equador até o polo sul. Os valores podem ser positivos e negativos dependendo do seu quadrante. Como unidade de medida, cada grau é composto de 60 minutos e cada minuto é composto de 60 segundos. Deste modo, a coordenada descrita na norma além de ultrapassar o valor numérico estipulado, não se enquadra nas instruções regulamentadas pelas normas técnicas da cartografia nacional.

Ainda nas especificações do artigo 2ํ, do Decreto Estadual no 15.618 (MARANHÃO, 1997):

continua seu limite passando pelo Conjunto Residencial dos Lusitanos até atingir o ponto de coordenadas geográficas latitude 2031'07,89”S e longitude 4412'38,64”'WGR localizado na parte inicial do Conjunto Residencial IPEM Turu (Ponto 3); daí passa pelo Parque Vitória, Loteamento Altos do Turu, até atingir o ponto de coordenadas geográficas latitude 2031'05,22'S e longitude 4411'31,19'WGR, localizado na convergência da Estrada da Vitória com a Estrada do Itapiracó (Ponto 4);sequenciando, percorre um trecho margeando a Estrada do Itapiracó, seguindo os limites do Loteamento Imobiliário SOTERRA, até atingir o ponto de coordenadas geográficas latitude $22^{\circ} 31^{\prime} 45,65^{\prime \prime} \mathrm{S}$ e longitude $44^{\circ} 11^{\prime} 25,60^{\prime} \mathrm{WGR}$ localizado no ponto de convergência do Loteamento Imobiliário SOTERRA com o Conjunto COHATRAC IV (Ponto 5); segue limitado pela Avenida Joaquim Mochel (COHATRAC IV) até atingir as coordenadas geográficas latitude 2031'57,26"S e longitude 4412'17,91”'WGR localizado no ponto de delimitação do COHATRAC IV com a área pretendida pela Associação dos Servidores do Ministério da Agricultura (Ponto 6); daí contorna a área pretendida pelos referidos servidores até encontrar o Ponto1.

Outra ressalva está no trecho "continua seu limite passando pelo Conjunto Residencial dos Lusitanos até atingir o ponto de coordenadas geográficas latitude 231'07,89'S e longitude 4412'38,64"WGR localizado na parte inicial do Conjunto Residencial IPEM Turu (Ponto 3) [grifos nossos]", o qual retrata a ausência de parâmetros de exatidão cartográfica na redação da norma. O uso do termo "passando" como linha limítrofe, é de sobremodo, salutar, haja vista dar ideia de ir de um local para outro. Entretanto, o uso do termo não determina corretamente onde seria a linha limítrofe, que atualmente é à margem da Rua Celso Coutinho. Além disso, o Residencial dos Lusitanos se localiza nas imediações do "Ponto 1", início da descrição, quando os confrontantes atualmente nesta parte são os Bairros Matões e Ipem Turu. E ainda, o "Ponto 3" também não está situado na extremidade da poligonal referente a APA do Itapiracó, a qual seria a interseção da Rua Celso Coutinho com a Rua da Vitória.

Em outro trecho, 'daí passa pelo Parque Vitória, Loteamento Altos do Turu, até atingir o ponto de coordenadas geográficas latitude 2³1'05,22”S e longitude 4411'31,19”'WGR, localizado na convergência da Estrada da Vitória com a Estrada do Itapiracó (Ponto 4) [grifos nossos]' fica mais uma vez claro a ausência de parâmetros de exatidão cartográfica, pois não determina a direção que se deve tomar para se deslocar ao 
próximo ponto. Ainda, o 'Ponto 4’ não está situado na exata interseção da Rua da Vitória com a Estrada do Itapiracó (atualmente Av. Jacarepaguá), quando na verdade localiza-se na margem da Estrada da Vitória, distando cerca de cento e sessenta e dois metros $(162 \mathrm{~m})$ da real bifurcação das estradas.

Já o trecho, '(...) sequenciando, percorre um trecho margeando a Estrada do Itapiracó, seguindo os limites do Loteamento Imobiliário SOTERRA, até atingir o ponto de coordenadas geográficas latitude 231'45,65'S e longitude 4411'25,60'WGR localizado no ponto de convergência do Loteamento Imobiliário SOTERRA com o Conjunto COHATRAC IV (Ponto 5) [grifos nossos]' gera dúvidas acerca da exata delimitação da área da APA do Itapiracó. Pois, dispõe em sequência a linha limítrofe, termo inadequado de acordo com as normas técnicas para levantamentos geodésicos (BRASIL, 1983), levantamentos topográficos - NBR 13.133 (ABNT, 1994), Normas técnicas para levantamento topográfico (BRASIL, 2001) e, ainda, georreferenciamento de imóveis rurais (BRASIL, 2013).

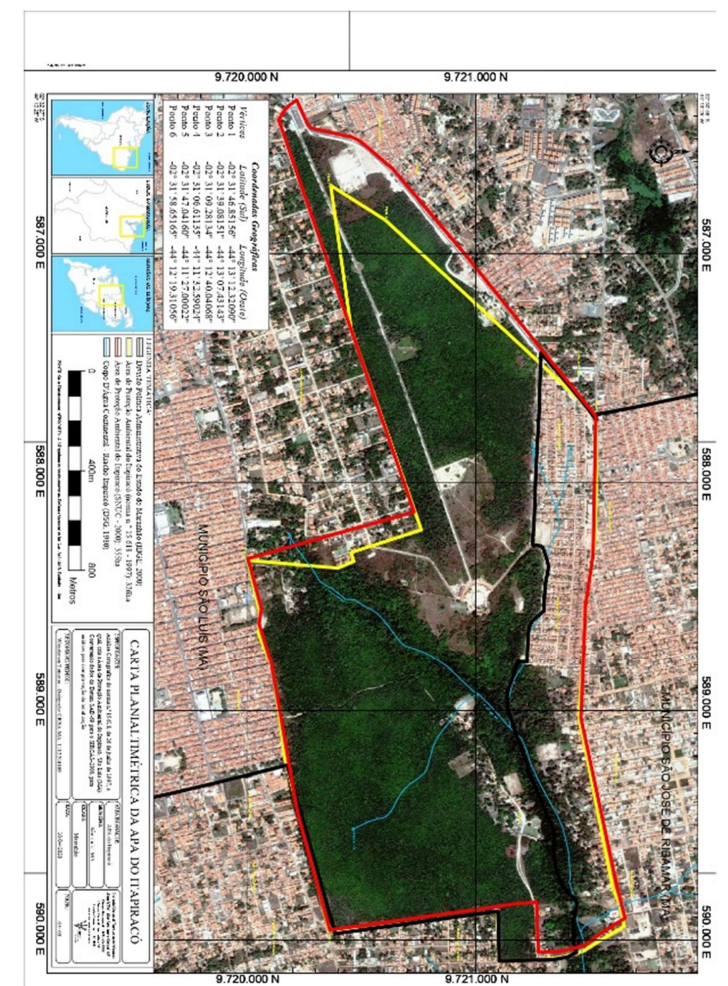

Figura 2: Análise cartográfica da APA do Itapiracó em mosaico de aerofotos.

O padrão técnico seria alocar um vértice de limite toda vez que a referida linha muda de direção. Essa situação gera dúvidas na delimitação da área da APA do Itapiracó que atualmente é um trecho das margens da Av. Jacarépaguá, Rua Santa Maria e, por fim, a Rua Costa e Silva. É importante mencionar que a descrição do confrontante também está equivocada, pois o 'Ponto 5' confronta-se ao Sul com o Bairro Novo Cohatrac, enquanto que o Bairro Cohatrac IV está distante cerca de setecentos e trinta e seis metros (736 m) à Oeste. E ainda, o 'Ponto 5', que está alocado no interior de um domicílio no Bairro Alto Itapiracó.

Ademais, 'segue limitado pela Avenida Joaquim Mochel (COHATRAC IV) até atingir as coordenadas geográficas latitude 231'57,26"S e longitude 4412'17,91”'WGR localizado no ponto de delimitação do COHATRAC IV com a área pretendida pela Associação dos Servidores do Ministério da Agricultura (Ponto 6) 
[grifos nossos]' é um trecho que deixa uma lacuna para consolidação da poligonal referente a área da APA do Itapiracó, já que a Av. Joaquim Mochel está distante cerca de setecentos e trinta e seis metros (736 m) à Oeste do ponto anterior do descritivo.

O trecho final da descrição da área da APA do Itapiracó: 'daí contorna a área pretendida pelos referidos servidores até encontrar o Ponto1', remete a ideia de deslocar-se à volta de algum lugar, entretanto o uso do termo novamente não localiza corretamente onde seria a linha limítrofe. Esta situação dificulta a delimitação correta da poligonal referente a área da APA do Itapiracó, pois neste trecho ocorre um processo de ocupação oriunda do Bairro Chácara do Itapiracó (antiga área da Associação dos Servidores do Ministério da Agricultura).

\section{CONSIDERAÇÕES FINAIS}

As questões de limites em Unidades de Conservação e Áreas de Proteção Ambiental da Federação Brasileira não são assuntos recentes, contrário a isso, muitas são as divergências no que diz respeito aos seus domínios territoriais e político-administrativos. Não obstante, após uma decisão judicial, áreas de entorno da APA do Itapiracó (Residencial Canudos e Terra Livre) já passam por processos de regularização fundiária. Da mesma forma, inúmeros processos estão protocolados na justiça brasileira sobre o assunto.

Após análise do Decreto Estadual no 15.618 (MARANHÃO, 1997), o qual cria a Área de Proteção Ambiental do Itapiracó, concluiu-se pela necessidade de atualização da norma devido à ausência de parâmetros de exatidão cartográfica na redação, haja vista a constatação da ineficiência do decreto para estabelecer a poligonal referente à APA e, consequentemente, em proteger as nascentes do Riacho Itapiracó. Destaca-se, que duas das nascentes do Riacho Itapiracó, devido às pressões antrópicas (moradias), sofreram regressão da cabeceira de drenagem.

Constatou-se ainda, que após a sobreposição dos dados descritos na norma que cria a APA do Itapiracó (com área de 322 ha), com os dados disponibilizados no Cadastro Nacional de Unidades de Conservação - CNUC (BRASIL, 2000), do Ministério do Meio Ambiente (com área de 355 ha), ambos não concatenam com o que se acredita ser hoje a Área de Proteção Ambiental do Itapiracó. Além de incorporar em suas poligonais áreas referentes ao Residencial Terra Livre, Canudos e parte da Chácara Itapiracó, apresentam cálculos de áreas distintos. É importante mencionar que grande parte das obras públicas (praças, campos de futebol, quadras, estacionamentos, parquinhos infantis e circuitos de skate) estão alocados fora da área legalmente descrita na redação da norma em vigência.

Contudo, pretensa de regulamentação para os confrontantes da APA do Itapiracó, esta análise apresenta vários questionamentos, apontando distorções entre o descritivo e a cartografia dos vértices de limite da APA do Itapiracó.

\section{REFERÊNCIAS}


BRASIL. Decreto n. 6.666 de 27 de novembro de 2008. Institui, no âmbito do Poder Executivo federal, a Infraestrutura Nacional de Dados Espaciais - INDE. Brasília: DOU, 2008.

BRASIL. Decreto n. 89.817 de 20 de junho de 1984. Estabelece as Instruções Reguladoras das Normas Técnicas da Cartografia Nacional. Brasília: DOU, 1984.

BRASIL. Ministério da Agricultura, Pecuária e Abastecimento. Norma técnica para georreferenciamento de imóveis rurais. Brasília: INCRA, 2013.

BRASIL. Ministério da Agricultura, Pecuária e Abastecimento. Normas técnicas para levantamento topográfico. Brasília: INCRA, 2001.

BRASIL. Ministério do Meio Ambiente. Cadastro Nacional de Unidades de Conservação - Consultas por Unidades de Conservação. Brasília: MMA, 2000.

BRASIL. Ministério do Planejamento, Desenvolvimento e Gestão. Divisão regional do Brasil em Regiões Geográficas Imediatas e Regiões Geográficas Intermediárias. Rio de Janeiro: IBGE, 2017.

BRASIL. Ministério do Planejamento, Desenvolvimento e Gestão. Resolução da Presidência do IBGE n. 5 de 31 de março de 1993. Especificações e Normas Gerais para Levantamentos GPS: versão preliminar. Rio de Janeiro: IBGE, 1993.

BRASIL. Ministério do Planejamento, Desenvolvimento e Gestão. Resolução- PR n. 22, de 21 de julho de 1983. Especificações e Normas Gerais para Levantamentos Geodésicos em território brasileiro. Rio de Janeiro: IBGE, 1983.

ISSO. International Organization for Standardization. ISO 19115-1: Informações Geográficas - Metadados. Cuiabá: ISO, 2003.

MARANHÃO. Decreto n. 15.618 de 23 de junho de 1997. Cria a Área de Proteção Ambiental do Itapiracó. São Luís: DOE, 1997.

MARANHÃO. Lei Complementar n. 174 de 25 de maio de 2015. Dispõe sobre a instituição e gestão da Região Metropolitana da Grande São Luís. São Luís: DOE, 2015.

MARANHÃO. Lei Ordinária n. 10.650 de 31 de julho de 2017. Atualiza a Divisa Intermunicipal de Paço do Lumiar e São José de Ribamar. São Luís: DOE, 2017.

SPOSITO, E. S.. Geografia e Filosofia: Contribuição para o ensino do pensamento geográfico. São Paulo: UNESP, 2004.

A CBPC - Companhia Brasileira de Produção Científica (CNPJ: 11.221.422/0001-03) detém os direitos materiais desta publicação. Os direitos referem-se à publicação do trabalho em qualquer parte do mundo, incluindo os direitos às renovações, expansões e disseminações da contribuição, bem como outros direitos subsidiários. Todos os trabalhos publicados eletronicamente poderão posteriormente ser publicados em coletâneas impressas sob coordenação da Sustenere Publishing, da Companhia Brasileira de Produção Científica e seus parceiros autorizados. Os (as) autores (as) preservam os direitos autorais, mas não têm permissão para a publicação da contribuição em outro meio, impresso ou digital, em português ou em tradução. 